\title{
Knowledge, attitude, practice and associated factors towards post exposure prophylaxis to HIV infection among health care professionals in Debre Markos town public health institutions, Northwest Ethiopia, 2017
}

Background: HIV/AIDS is being considered as one of the major health problem and an occupational health hazard among health care personnel. Although avoiding contact with infected blood is one of the primary strategies of preventing occupationally acquired Human Immunodeficiency Virus infection, appropriate post-exposure management is an important element in work place safety.

Objective: To assess knowledge, attitude, practice and associated factors towards post exposure prophylaxis to HIV infection among Health Care Professionals.

Methods: A quantitative descriptive cross-sectional study was conducted using self-administered questionnaire. After data was coded, entered in to Epi data 3.1, and transported to SPSS version20 for analysis. To see the Association between dependent and independent variables binary and multi logistic regression was done.

Results: Among 202 participants, more than two third 120 (59.4\%) were male and $152(75.2 \%)$ in the age group of 2030 years and the mean age was 29.46 years and SD5.961. The study finding revealed that $36.1 \%$ inadequate knowledge towards PEP. About 30.2\% had unfavorable attitude towards PEP. With regard to practice from 67(33.2\%) of exposed respondents, 29 (43.3\%) took PEP. According to this finding 53.2\% of health professionals were started PEP after 1 hour of exposure. Profession and attitude were strongly associated with knowledge of study participants $(P=0.014$, and $P=0.002)$. Knowledge was significantly associated with attitude $(P=0.001)$.

Conclusion and Recommendation: Despite adequate knowledge and favorable attitude towards PEP for HIV, this study revealed that there were delay initiation, low use and incomplete use of the prescribed drug of PEP. So, health care personnel need to improve their practice on PEP of HIV through different training program related to PEP.

Keywords: health care professionals, post exposure prophylaxis, HIV, knowledge, attitude, practice

\section{List of abbreviations and acronyms:}

AIDS- Acquired Immune Deficiency Syndrome; ART- Anti Retroviral Therapy; ARVAntiretroviral; AZT- Zidovudine; BBV- Blood Borne Viruses; BSc- Bachelor of science; CDCCenters for Disease Control and Prevention; CI- Confidence Interval; 3TC-Lamivudine; EDHS- Ethiopia Demographic and Health Survey; FMOH: - Federal Minister of Health; HCP- Health Care Personnel; HCWs-Health Care Workers; HIV- Human Immunodeficiency Virus; HIV/AIDS- Human Immunodeficiency Virus/ Acquired Immune Deficiency
Syndrome; Pep- Post-Exposure Prophylaxis; SPSS- Statistical Package for Social Sciences; TDF-Tenofovir; WHO /IOL- World Health Organization /International Organization of Labor; WHO -World Health Organization.

\section{Background}

HIV/AIDS is being considered as one of the major health problem and an occupational health hazard among health care personnel. Although avoiding contact with infected blood is one of the primary strategies of preventing occupationally acquired Human Immunodeficiency Virus (HIV) infection,
Biyadgie Aschale ${ }^{1}$, Yenesew Tamir ${ }^{1}$, Girma Alem*2

${ }^{1}$ School of Medicine, Debremarkos University, Debremarkos, Amhara, Ethiopia

${ }^{2}$ Department of Nursing, Health Science College, Debremarkos University, Debremarkos, Amhara, Ethiopia

*Author for correspondence: girmaalem95@gmail.com 
appropriate post-exposure management (PEP) is an important element in work place safety [1].

After exposure, HIV replicates within dendritic cells of the skin and mucous before spreading through the lymphatic vessels and develops into systemic infection. This delay in the systemic spread gives an opportunity for PEP using designed to block replication of HIV [2]. Even though the maximum delay for initiation of treatment to prevent infection is not known in human. The CDC recommendations are to offer prophylaxis up to 24 to 36 hours after exposure (No consideration of PEP beyond 72 hours) $[3,4]$.

Patients often present to emergency departments or primary care providers after possible exposure to HIV. Several issues may be addressed at the first consultation, including determining whether an exposure has occurred and, if so, the risk of transmission. If an exposure is likely to have occurred, there should be a discussion about post exposure prophylaxis [5]. PEP includes first aid, counseling, risk assessment, relevant laboratory investigations based on the informed consent of the exposed person and source and following the risk assessment, provision of short term of antiretroviral drugs for 28 days, along with follow-up evaluation $[6,7]$.

Preventing exposures to blood and body fluids (i.e., 'primary prevention') is the most important strategy for preventing occupationally acquired human immunodeficiency virus (HIV) infection. Both individual healthcare providers and the institutions that employ them should work to ensure adherence to the principles of "Standard Precautions," including assuring access to and consistent use of appropriate work practices, work practice controls, and personal protective equipment [8].

Workers and employers are urged to take advantage of available engineering controls and work practices to prevent exposure to blood and other body fluids [9].

Health care professionals (HCWs) potentially exposed to infectious materials such as blood, tissue, specific body fluids, medical supplies, equipment or environmental surfaces contaminated with these substances [10]. They are frequently exposed to occupational hazards through percutaneous injury such as needle stick or cut with sharps, contact with the mucus membrane of eyes or mouth of an infected person, contact with non-intact skin exposed with blood or other potentially infectious body fluids [11-25].

It is necessary to initiate the prophylaxis measure in order to minimize the chance of HIV establishment. Hence, Ethiopia has developed guideline on the prevention of infection in health institutions in July 2004 and also employed the use of post exposure prophylaxis since the implementation of free antiretroviral in January 2005 [7].

\section{Objectives}

- To determine the level of knowledge towards PEP to HIV/AIDS infection among health care Professionals.

- To determine the level of attitudes towards PEP to HIV/AIDS infection among health care Professionals.

- To determine the level of practice towards PEP to HIV/AIDS infection among health care Professionals.

- To identify associated factor that affects knowledge, attitude, and practice towards PEP.

\section{Methods and materials}

\section{- Study area and period}

The study was conducted in Debre Markos Town Public Health Institutions (Debre Markos Referral Hospital, Debre Markos Health Center, Hidassie and Wuseta Health Center). Debremarkos town is found in NorthWest Ethiopia $300 \mathrm{Km}$ away from capital city of Ethiopia, Addis Ababa and $265 \mathrm{~km}$ from Bahidar the capital city of Amhara Regional State. Data was collected from $13^{\text {th }}$ February to 30 ${ }^{\text {th }}$ February, 2017.

\section{Study design}

An institutional based cross-sectional study was conducted by using standardized structured administered questionnaire. Self-administered structured questionnaire was developed in order to collect the study data from participants.

\section{Source population}

All Health Care Professionals who are working in Debre Markos Town Public Health Institutions. The study participants were all Health Care Professionals that fulfill the inclusion criteria. 


\section{- Inclusion and exclusion criteria}

All Health Care Professionals working in Debre Markos Town Public Heath Institutions and fully involved during the study period was included. Health Care Personnel who are working in the office and not potentially exposed for HIV risky conditions (Pharmacy, Admission Officers, Radiographer and Environmental Health) were excluded.

\section{- Sample size}

The sample size was determined using single proportion formula $n=(Z \alpha / 2) 2 P(1-p) / d 2$ and by considering the following assumptions: 95\% CI, Where, $\mathrm{Z} \alpha / 2=1.96$

$\mathrm{P}=$ prevalence of $63.1 \% \quad(23) . \mathrm{d}=5 \%$ of marginal error was taken. By using correction formula 184 samples were obtained. The overall sample size was found to be $184+18$ (10 \% nonresponses) $=202$.

\section{- Sampling procedures}

The total sample size was distributed proportionally across different Health Care Professionals involved in this study and sampling frame took from each department head in each institution, the study subjects was selected using simple random sampling technique

\section{- Study variables}

Dependent variable

Knowledge, attitudes and practice towards HIV Post Exposure Prophylaxis.

\section{Independent variable}

1. Socio demographic factors (sex, age, profession, educational status, monthly income, Work experience).

2. Information source on PEP, knowing about the presence of guide line for PEP management and training obtained.

3. Behavioral factors: Chat chewing, Smoking, Alcohol drinking

4. Environmental factors: Work place (Unit/ward), Work load

\section{- Operational definitions}

Scoring of Knowledge, Attitude and Practice Questions,
Twelve questions, with "Yes" (for correct answers) or "No" (for incorrect answers) response and choice, was prepared to assess the knowledge of respondents about PEP for HIV and those respondents who scored greater than or equal to $70 \%$ were considered Knowledgeable [23].

A seven item question was used to assess participants' attitude towards PEP for HIV and those who score $70 \%$ and above were considered as having good attitude [23]. (Favorable attitude-Agree and strongly agree) and (Unfavorable attitude-Neutral, Disagree and strongly disagree)

To assess the practice of respondents' nine questions were prepare and those who answer "Yes" to more than $70 \%$ of the questions was considered as practicing PEP for HIV [23].

\section{Data collection methods and instrument}

Self-administered structured questionnaire was developed in order to collect the study data from participants. The questionnaire consists of five parts; which include socio-demographic, knowledge, attitude, practice and associated factors questions [23].

\section{- Data analysis and management}

All returned questionnaires were checked for completeness, inconsistencies of response manually; coded, entered into Epi-data version 3.1 and transformed to SPSS 20 version statistical software to be analyzed. Appropriate descriptive statistics and analytical (frequency, mean, standard deviation and chart was used to determine the prevalence and statistically significant association between the dependent variables using OR. P-value less than 0.05 were considered statistically significant.

\section{Ethical considerations}

Ethical clearance was obtained from the Ethical Committee of Health Science College, Debre Markos University. Then formal letter of cooperation was written to Debre Markos Town Health Institutions to obtain their consent. Study participants were informed about purposes of the study and its procedures. Oral consent was obtained from each participant. Confidentiality was maintained. 


\section{Results \\ - Socio-demographic characteristics of the study population}

Among the total participants 152 (75.2\%) were in the age group of 20-30 years and the mean age was 29.46 years and SD 5.96. More than two third $120(59.4 \%)$ were male. One hundred three $(51.0 \%)$ participants were single. Regarding their educational status of respondents 154 (76.2\%) were First Degree holders. Majority of the study participants 167 $(82.7 \%)$ were from Hospital and 79 (39.1\%) of the professionals were from inpatient department (ward) and outpatient department 64 (31.7\%). One hundred nineteen (58.9\%) had less than five years' service; the mean work experience of the respondents was 6.14 years. Out of the total respondent $112(55.4 \%)$ earn a monthly income less than mean 4258 Birr. Regarding patient care about 116 (57.4\%) of the study participant given care for less than 35 patients per day (TABLE 1).

\section{Knowledge of Health Care Profes- sionals towards PEP for HIV}

Majority of $129(63.9 \%)$ the participants had adequate knowledge about PEP for HIV. Regarding to the source of information about PEP out of 202 respondents, 105 (52.0\%) heard about PEP from formal training. Majority, 156 (77.2\%) of the participants of the study answered that PEP is indicated for person who

Table 1. Socio-demographic characteristics of health care professionals working in public health institutions in Debre Markos town, Feb-Mar 2017.

\begin{tabular}{|c|c|c|c|}
\hline Variables & Category & Number & Percent (\%) \\
\hline \multirow{2}{*}{ Sex } & Male & 120 & 59.4 \\
\hline & Female & 82 & 40.6 \\
\hline \multirow{3}{*}{ Age } & $20-30$ years & 152 & 75.2 \\
\hline & $31-40$ years & 37 & 18.3 \\
\hline & $\geq 41$ years & 13 & 6.5 \\
\hline \multirow{2}{*}{ Marital status } & Single & 103 & 51.0 \\
\hline & Married and separated & 99 & 49.0 \\
\hline \multirow{2}{*}{ Religion } & Orthodox Christian & 194 & 96.0 \\
\hline & Others & 8 & 4.0 \\
\hline \multirow{2}{*}{ Place of work } & Hospital & 167 & 82.7 \\
\hline & Health center & 35 & 17.3 \\
\hline \multirow{7}{*}{ Profession } & Medical doctor & 42 & 20.8 \\
\hline & Emergency surgeon & 2 & 1.0 \\
\hline & Nurse & 104 & 51.5 \\
\hline & Midwife & 19 & 9.4 \\
\hline & Laboratory & 25 & 12.4 \\
\hline & Anesthetists & 4 & 2.0 \\
\hline & Public health & 6 & 3.0 \\
\hline \multirow{4}{*}{ Educational level } & Diploma & 41 & 20.3 \\
\hline & First Degree & 154 & 76.2 \\
\hline & Master Degree & 4 & 2.0 \\
\hline & Specialist & 3 & 1.5 \\
\hline \multirow{3}{*}{ Service year } & $\leq 5$ years & 119 & 58.9 \\
\hline & $6-10$ years & 62 & 30.7 \\
\hline & $>10$ years & 21 & 10.4 \\
\hline \multirow{5}{*}{ Working Department } & Outpatient Department & 70 & 34.7 \\
\hline & Delivery room & 15 & 7.4 \\
\hline & Ward & 79 & 39.1 \\
\hline & Operation room & $14 s$ & 6.9 \\
\hline & Laboratory & 24 & 11.9 \\
\hline \multirow{2}{*}{ Monthly income in Ethiopian Birr } & $<4258$ (below mean) & 112 & 55.4 \\
\hline & >_4258(Above mean) & 90 & 44.6 \\
\hline \multirow{2}{*}{ Patient care } & $\leq 35$ patients/day & 116 & 57.4 \\
\hline & $\geq 35$ patients/day & 86 & 42.6 \\
\hline
\end{tabular}


Knowledge, attitude, practice and associated factors towards post exposure prophylaxis to HIV infection among health care professionals in Debre Markos town public health institutions, Northwest Ethiopia, 2017

is exposed to HIV risk if the patient is known to be HIV positive and moucocutaneous exposure, followed by person who is exposed to HIV if the source patient is at high risk for HIV $105(52.0 \%)$. From the study participants $152(75.2 \%)$ answered that PEP for HIV is efficient and 158 (78.2\%) knew when to initiate PEP. One hundred sixty seven $(82.7 \%)$ of the respondents knew the maximum acceptable delay to take PEP and 190 (94.0\%) knew for how long exposed individuals should be on PEP to prevent infection (TABLE 2). As shown in FIGURES 1 and 2 among the total 42 medical doctors 40 (95.2\%) had adequate knowledge.

\section{- Associated factors affecting knowledge level of health care professionals}

Multivariate logistic regression analysis was done for factors with P-value of-less than 0.25 in bivariate analysis to see the association among variables. According to the multivariate logistic regression analysis result, profession and attitude status was found to have significant association with knowledge regarding to PEP. The odds of PEP Knowledge status were 3 times higher among those who had favorable attitude on PEP when compared with those had unfavorable attitude on PEP. (AOR $=0.11$, 95\% CI .02 -.64) and (AOR=3.17, 95\% CI (1.54$6.46)$. On other variables, like age did not show an association (TABLE 3).

\section{Attitude of the health care professionals towards PEP}

Majority of the respondents, 141 (69.8\%) were favorable attitude towards PEP for HIV. One hundred sixty three $(80.7 \%)$ respondents

Table 2. Response of Health Care Professionals to knowledge questions about PEP, working in Public Health Institutions in Debre Markos Town, Feb-Mar 2017.

\begin{tabular}{|c|c|c|c|c|c|}
\hline \multicolumn{3}{|c|}{ Knowledge questions } & Responses & Frequency & Percent (\%) \\
\hline \multirow{2}{*}{\multicolumn{2}{|c|}{ Level of Knowledge towards PEP }} & \multicolumn{2}{|c|}{ Adequate knowledge } & 129 & 63.9 \\
\hline & & \multicolumn{2}{|c|}{ Inadequate knowledge } & 73 & 36.1 \\
\hline \multirow{2}{*}{\multicolumn{3}{|c|}{ Heard about PEP }} & Yes & 202 & 100.0 \\
\hline & & & No & 0 & 0 \\
\hline \multirow{12}{*}{$\begin{array}{l}\text { When PEP } \\
\text { should be } \\
\text { indicated }\end{array}$} & \multirow{2}{*}{\multicolumn{2}{|c|}{ When the source patient is at high risk for HIV }} & Yes & 105 & 52.0 \\
\hline & & & No & 97 & 48 \\
\hline & \multirow{2}{*}{\multicolumn{2}{|c|}{$\begin{array}{l}\text { When the patient is known to be HIV positive } \\
\text { and mucocutaneous exposure }\end{array}$}} & Yes & 156 & 77.2 \\
\hline & & & No & 46 & 22.8 \\
\hline & \multirow{2}{*}{\multicolumn{2}{|c|}{$\begin{array}{l}\text { When the HIV status of the source is unknown } \\
\text { and exposed on intact skin }\end{array}$}} & Yes & 33 & 16.3 \\
\hline & & & No & 169 & 83.7 \\
\hline & \multirow{2}{*}{\multicolumn{2}{|c|}{ For any needle stick injury in the work place }} & Yes & 56 & 27.7 \\
\hline & & & No & 146 & 72.3 \\
\hline & \multirow{2}{*}{\multicolumn{2}{|c|}{$\begin{array}{l}\text { Contact with patient body fluids (urine, saliva, } \\
\text { sweat) }\end{array}$}} & Yes & 13 & 6.4 \\
\hline & & & No & 189 & 93.6 \\
\hline & \multirow{2}{*}{\multicolumn{2}{|c|}{$\begin{array}{l}\text { Contact with patient body fluids (amniotic fluid, } \\
\text { CSF, peritoneal fluid) }\end{array}$}} & Yes & 69 & 34.2 \\
\hline & & & No & 133 & 65.8 \\
\hline \multirow{4}{*}{\multicolumn{2}{|c|}{ Maximum delay to take PEP }} & \multicolumn{2}{|l|}{ 12hours } & 10 & 5.0 \\
\hline & & \multicolumn{2}{|l|}{ 24hours } & 10 & 5.0 \\
\hline & & \multicolumn{2}{|l|}{ 48hours } & 15 & 7.4 \\
\hline & & \multicolumn{2}{|l|}{ 72hours } & 167 & 82.7 \\
\hline \multirow{4}{*}{\multicolumn{2}{|c|}{ Golden time to take PEP }} & \multicolumn{2}{|c|}{ Within an hour } & 158 & 78.2 \\
\hline & & \multicolumn{2}{|c|}{ After 6 hour of exposure } & 24 & 11.9 \\
\hline & & \multicolumn{2}{|c|}{ After 12 hour of exposure } & 14 & 6.9 \\
\hline & & \multicolumn{2}{|c|}{ After 72 hour of exposure } & 6 & 3.0 \\
\hline \multirow{4}{*}{\multicolumn{2}{|c|}{ Effectiveness of PEP }} & \multicolumn{2}{|c|}{$100 \%$} & 14 & 6.9 \\
\hline & & \multicolumn{2}{|l|}{$80-100 \%$} & 152 & 75.2 \\
\hline & & \multicolumn{2}{|l|}{$60-70 \%$} & 30 & 14.9 \\
\hline & & \multicolumn{2}{|l|}{$30-50 \%$} & 6 & 3.0 \\
\hline \multirow{4}{*}{\multicolumn{2}{|c|}{ Length of time to take PEP }} & \multicolumn{2}{|l|}{ For 28days } & 190 & 94.0 \\
\hline & & \multicolumn{2}{|l|}{ For 40days } & 5 & 2.5 \\
\hline & & For six month & & 5 & 2.5 \\
\hline & & For lifetime & & 2 & 1.0 \\
\hline
\end{tabular}


were strongly agree that PEP is important for HIV and 138 (68.3\%) strongly agree Training of PEP is important for a behavioral change (TABLE 4).

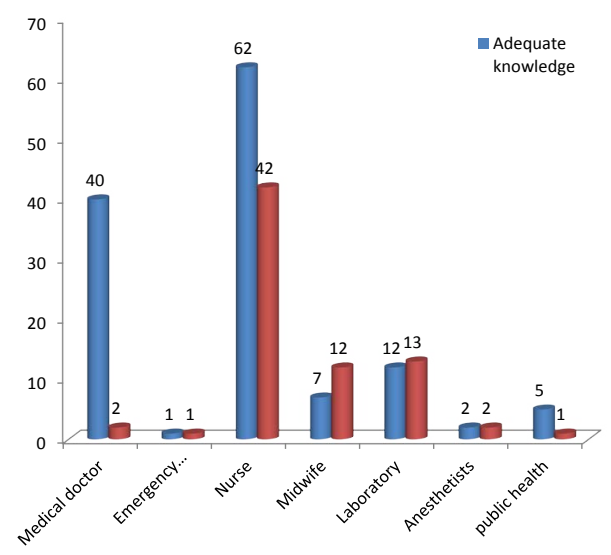

Figure 1. Frequency of participant's based on profession and knowledge status distribution, 2017.

\section{Associated factors affecting attitude level of health care professionals}

Multivariate logistic regression analysis was done for factors with P-value of-less than 0.25 in bivariate analysis to see the association among variables. According to the multivariate logistic regression analysis result, knowledge status was found to have significant association with PEP attitude. The odds of PEP attitude status were 3.2 times higher among those who had adequate knowledge on PEP when compared with those had inadequate knowledge on PEP. $(\mathrm{AOR}=3.21$,

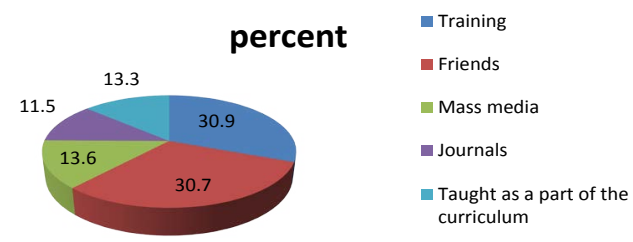

Figure 2. Participant's Source of Information about PEP, 2017.

\begin{tabular}{|c|c|c|c|c|c|c|}
\hline \multirow{2}{*}{\multicolumn{2}{|c|}{ Variables }} & \multicolumn{2}{|c|}{ Knowledge status } & \multirow{3}{*}{$\begin{array}{c}\text { P- } \\
\text { value }\end{array}$} & \multirow{3}{*}{$\begin{array}{c}\text { COR(95\%Cl) } \\
1\end{array}$} & \multirow{3}{*}{$\begin{array}{c}\text { AOR(95\%Cl) } \\
1 \\
\end{array}$} \\
\hline & & \multirow{2}{*}{$\begin{array}{l}\text { Adequate } \\
82(63.3 \%)\end{array}$} & \multirow{2}{*}{$\begin{array}{c}\text { Inadequate } \\
38(31.7 \%)\end{array}$} & & & \\
\hline & Male & & & & & \\
\hline Sex & Female & 47 (59.4\%) & 35 (40.6\%) & 0.961 & $\begin{array}{c}0.622(0.348- \\
1.11)\end{array}$ & $1.018(0.50-2.08)$ \\
\hline \multirow[b]{2}{*}{ Marital status } & Single & $71(68.9 \%)$ & $32(31.2 \%)$ & & 1 & 1 \\
\hline & $\begin{array}{c}\text { Married and } \\
\text { separated }\end{array}$ & $58(58.6 \%)$ & $41(41.4 \%)$ & 0.71 & $0.64(0.36-1.14)$ & $0.856(0.38-1.9)$ \\
\hline \multirow{5}{*}{$\begin{array}{l}\frac{c}{\tilde{n}} \\
\frac{\mathscr{W}}{0} \\
\frac{0}{\alpha}\end{array}$} & Medical doctor & $40(95.2 \%)$ & $2(4.8 \%)$ & & 1 & 1 \\
\hline & Nurse & $62(59.6 \%)$ & $42(39.4 \%)$ & 0.013 & $0.07(0.02-0.32) *$ & $0.112(0.02-0.62)^{*}$ \\
\hline & Midwife & 7 (36.8\%) & $12(63.2 \%)$ & 0.003 & $0.29(0.01-0.16) *$ & $0.042(0.01-0.35)^{*}$ \\
\hline & Laboratory & $12(48 \%)$ & $13(52 \%)$ & 0.003 & $0.05(0.01-0.23) *$ & $0.040(0.01-0.34)^{*}$ \\
\hline & Others ${ }^{* *}$ & $8(66.6 \%)$ & $4(33.3 \%)$ & 0.047 & & $0.116(.01-.97)^{*}$ \\
\hline \multirow{3}{*}{$\begin{array}{c}\text { Educational } \\
\text { level }\end{array}$} & Diploma & $19(46.3 \%)$ & $22(53.7 \%)$ & 0.622 & $0.42(0.21-0.84)$ & $0.79(0.30-2.05)$ \\
\hline & First Degree & $104(67.5 \%)$ & $50(32.5 \%)$ & & 1 & 1 \\
\hline & $\begin{array}{c}\text { Master's Degree } \\
\text { and above }\end{array}$ & $6(85.7 \%)$ & $1(14.3 \%)$ & 0.639 & $1.44(0.15-14.22)$ & $1.76(0.16-18.95)$ \\
\hline \multirow{3}{*}{ Service year } & $\leq 5$ years & $84(70.6 \%)$ & $35(29.4 \%)$ & & 1 & 1 \\
\hline & $6-10$ years & $32(51.5 \%)$ & $30(48.5 \%)$ & 0.747 & $0.44(0.24-0.84) *$ & $0.87(0.37-2.04)$ \\
\hline & $>10$ years & 13(61.9\%) & $8(38.1 \%)$ & 0.942 & $0.68(0.26-1.77)$ & $0.954(0.27-3.40)$ \\
\hline \multirow{3}{*}{ Unit of Work } & OPD & $51(72.3 \%)$ & $19(27.7 \%)$ & & 1 & 1 \\
\hline & Ward & $51(64.5 \%)$ & $28(35.5 \%)$ & 0.60 & $0.68(0.34-1.4)$ & $0.80(0.35-1.85)$ \\
\hline & Others *** & $27(50.9 \%)$ & $26(49.1 \%)$ & 0.63 & & $1.35(0.40-4.49)$ \\
\hline \multirow{2}{*}{$\begin{array}{l}\text { Monthly } \\
\text { income }\end{array}$} & $<4258$ & $61(54.5 \%)$ & $51(45.5 \%)$ & & 1 & 1 \\
\hline & $>\_4258$ & $68(77.3 \%)$ & $22(22.7 \%)$ & 0.952 & $2.58(1.41-4.75) *$ & $1.029(0.41-2.59)$ \\
\hline \multirow{2}{*}{ Attitude status } & Unfavorable & 103(73\%) & $38(27 \%)$ & & 1 & 1 \\
\hline & Favorable & $26(42.6 \%)$ & $35(57.4 \%)$ & 0.002 & $3.64(1.95-6.85) *$ & $3.17(1.54-6.46)$ * \\
\hline \multicolumn{7}{|c|}{$\begin{array}{l}\text { NB *shows significant association } \\
\text { **Others (Public Health, Anesthetists, Emergency Surgeon) } \\
\text { ***others (Delivery Room, Laboratory, Operation Room) }\end{array}$} \\
\hline
\end{tabular}


Knowledge, attitude, practice and associated factors towards post exposure prophylaxis to HIV infection among health care professionals in Debre Markos town public health institutions, Northwest Ethiopia, 2017

95\% CI (1.60-6.45). On other variables, like age, sex, marital status, profession and service year did not show an association (TABLE 5).

\section{Dractice status of the health care professionals towards PEP for HIV}

Among all of the respondents, 67 (33.2\%) of them were exposed for HIV/AIDS risky conditions and 38/ (56.7\%) didn't took PEP. Immediate measures taken after exposure, Washed with soap and water was the most common 46(68.6\%) followed by squeezing for more bleeding and washed with alcohol or disinfectant $10(14.9 \%)$. In this result major reason for individuals who didn't receive PEP following their exposure were whose HIV test result was negative $20(52.6 \%)$ and negligence $12(31.5 \%)$. Among those respondents who took PEP, 19/29 (65.5\%) had complete the prescribed PEP. The major reason for discontinue was fear of its adverse effects7/10 (50\%) and negligence $3 / 10$ (30\%) (TABLE 6).

Associated factors affecting practice of health care professionals

Multivariate logistic regression analysis was done for factors with P-value of-less than 0.25 in bivariate analysis to see the association among variables. In this study, there were no factors

\begin{tabular}{|c|c|c|c|c|c|}
\hline \multirow{5}{*}{ Variables } & \multicolumn{3}{|c|}{ Attitude status } & Frequency & Percent (\%) \\
\hline & \multicolumn{3}{|c|}{ Favorable attitude } & 141 & 69.8 \\
\hline & \multicolumn{3}{|c|}{ Unfavorable attitude } & 61 & 30.2 \\
\hline & \multicolumn{3}{|c|}{ Total } & 202 & 100.0 \\
\hline & $\begin{array}{l}\text { Strongly } \\
\text { disagree }\end{array}$ & Disagree & Neutral & Agree & $\begin{array}{l}\text { Strongly } \\
\text { agree }\end{array}$ \\
\hline Important of PEP & $2(1.0 \%)$ & $3(1.5 \%)$ & $1(0.5 \%)$ & $33(16.3 \%)$ & $163(80.7 \%)$ \\
\hline $\begin{array}{l}\text { Training of PEP is important for a behavioral } \\
\text { change }\end{array}$ & $9(4.5 \%)$ & $5(2.5 \%)$ & $5(2.5 \%)$ & $45(22.3 \%)$ & $138(68.3 \%)$ \\
\hline there should be PEP guideline in work areas & $7(3.5 \%)$ & $7(3.5 \%)$ & $9(4.5 \%)$ & $48(23.8 \%)$ & $131(64.9 \%)$ \\
\hline $\begin{array}{l}\text { PEP reduces the likelihood of being HIV } \\
\text { positive }\end{array}$ & $8(4.0 \%)$ & $68(33.7 \%)$ & $9(4.5 \%)$ & $68(33.7 \%)$ & $111(55.0 \%)$ \\
\hline PEP use to prevent further infection & $63(31.2 \%)$ & $32(15.8 \%)$ & $19(9.4 \%)$ & $56(27.7 \%)$ & $32(15.8 \%)$ \\
\hline PEP is indicated for any sharp injury & $25(12.4 \%)$ & $50(24.8 \%)$ & $40(19.8 \%)$ & $48(23.8 \%)$ & $39(19.3 \%)$ \\
\hline $\begin{array}{l}\text { Opinion on PEP is not important if the } \\
\text { exposure is not with pt. blood of known HIV } \\
\text { positive? }\end{array}$ & $52(25.7 \%)$ & $33(16.3 \%)$ & 41 (20.3\%) & $50(24.8 \%)$ & $26(12.9 \%)$ \\
\hline
\end{tabular}

Table 5. Regression analysis attitude and associated factors for Health Care Professionals towards PEP in Debre Markos Town Public Health Institutions, Feb-Mar. 2017.

\begin{tabular}{|c|c|c|c|c|c|c|}
\hline \multicolumn{2}{|l|}{ Variables } & \multicolumn{2}{|c|}{ Attitude status } & \multirow[t]{2}{*}{ P-value } & \multirow[t]{2}{*}{ COR(95\%Cl) } & \multirow[t]{2}{*}{ AOR(95\%Cl) } \\
\hline & & Favorable & Unfavorable & & & \\
\hline \multirow{5}{*}{$\begin{array}{l}\frac{0}{\tilde{N}} \\
\frac{\tilde{\omega}}{\underline{0}} \\
\frac{0}{2}\end{array}$} & Medical doctor & $37(88.1 \%)$ & $5(11.9 \%)$ & & 1 & 1 \\
\hline & Nurse & $67(64.4 \%)$ & $37(35.6 \%)$ & 0.16 & $0.25(0.10-0.77)$ & $0.42(0.13-1.39)$ \\
\hline & Midwife & $8(42.1 \%)$ & $11(57.9 \%)$ & 0.18 & $0.11(0.03-0.36)$ & $0.31(0.05-1.73)$ \\
\hline & Laboratory & $21(84 \%)$ & $4(16 \%)$ & 0.35 & $0.71(0.17-2.93)$ & $2.5(0.37-17.11)$ \\
\hline & Others & $8(66.7 \%)$ & $4(33.3 \%)$ & 0.39 & $0.27(0.06-1.24)$ & $0.48(0.09-2.57)$ \\
\hline \multirow{3}{*}{ Unit of Work } & OPD & $51(72.6 \%)$ & $19(27.4 \%)$ & & 1 & 1 \\
\hline & Ward & $56(70.9 \%)$ & $23(29.1 \%)$ & 0.62 & $0.91(0.44-1.86)$ & $1.22(0.56-2.69)$ \\
\hline & Others & $34(64.1 \%)$ & $19(35.9 \%)$ & 0.29 & $0.67(0.31-1.44)$ & $0.54(0.17-1.72)$ \\
\hline \multirow{2}{*}{$\begin{array}{l}\text { Monthly } \\
\text { income }\end{array}$} & $<4258$ & $72(64.3 \%)$ & $40(35.7 \%)$ & & 1 & 1 \\
\hline & $\geq 4258$ & $69(76.7 \%)$ & $21(23.3 \%)$ & 0.99 & $0.55(0.29-1.02)$ & $1.01(0.46-2.19)$ \\
\hline \multirow{2}{*}{ Training } & Yes & $80(56.7 \%)$ & $61(43.3 \%)$ & 0.07 & $1.89(1.0-3.47)^{*}$ & $1.89(0.95-3.78)$ \\
\hline & No & $25(40.9 \%)$ & $36(59.1 \%)$ & & 1 & 1 \\
\hline \multirow{2}{*}{$\begin{array}{l}\text { Knowledge } \\
\text { status }\end{array}$} & Adequate & $103(79.8 \%)$ & $26(20.2 \%)$ & 0.001 & $3.65(1.95-6.8)^{*}$ & $3.21(1.60-6.45)^{*}$ \\
\hline & Inadequate & $38(52.1 \%)$ & $35(47.9 \%)$ & & 1 & 1 \\
\hline
\end{tabular}


associated with Post exposure prophylaxis use

(TABLE 7).

Work environment and behavioral characteristics of health care professionals
From the study participants, 104 (51.5\%) didn't know PEP guidelines. One hundred eighteen $(58.4 \%)$, there is no written protocol for reporting their exposure conditions in their workplace (TABLE 8).

Table 6. Practice of PEP for Health Care Professionals in Debre Markos Town Public Health Institutions, Feb-Mar. 2017.

\begin{tabular}{|c|c|c|c|}
\hline Practice variables & Response & Frequency & Percent (\%) \\
\hline \multirow{2}{*}{$\begin{array}{l}\text { Have you ever been exposed to HIV } \\
\text { risky conditions? }\end{array}$} & Yes & 67 & 33.2 \\
\hline & No & 135 & 66.8 \\
\hline \multirow{2}{*}{ How many times you exposed? } & One time & 37 & 55.2 \\
\hline & Two and more than times & 30 & 44.8 \\
\hline \multirow{4}{*}{ Action taken at the time of exposure } & Nothing & 8 & 11.9 \\
\hline & Wash the wound with soap and water & 46 & 68.6 \\
\hline & $\begin{array}{l}\text { Squeeze and wash with alcohol or } \\
\text { disinfectant }\end{array}$ & 10 & 14.9 \\
\hline & Consult to appropriate physician & 3 & 4.6 \\
\hline \multirow{2}{*}{ Took PEP after exposure } & Yes & 29 & 43.3 \\
\hline & No & 38 & 56.7 \\
\hline \multirow{2}{*}{ Reason to took PEP } & Exposure to blood from known HIV & 26 & 89.7 \\
\hline & Contact with patient body fluids & 3 & 10.3 \\
\hline \multirow[t]{3}{*}{ The time to start taking PEP } & Within1hour & 13 & 44.8 \\
\hline & After 2-6 hrs of exposure & 10 & 34.5 \\
\hline & After $6 \mathrm{hrs}$ of exposure & 6 & 20.7 \\
\hline \multirow{2}{*}{ completed the prescribed drug of PEP } & Yes & 19 & 65.5 \\
\hline & No & 10 & 34.5 \\
\hline \multirow{3}{*}{$\begin{array}{l}\text { A period of time that a respondent } \\
\text { took PEP }\end{array}$} & $<1 \mathrm{wk}$ & 4 & 13.7 \\
\hline & $2-3$ wks & 6 & 20.7 \\
\hline & 4 wks & 19 & 65.6 \\
\hline \multirow{2}{*}{ Reason for discontinuation of the drug } & Fear of adverse effects & 7 & 70 \\
\hline & Negligence & 3 & 30 \\
\hline \multirow{3}{*}{ Reason for didn't take PEP drugs } & Source patient HIV negative & 20 & 52.6 \\
\hline & Negligence and Unaware of PEP & 12 & 31.5 \\
\hline & Splash on intact skin & 6 & 15.9 \\
\hline
\end{tabular}

Table 7. Regression analysis of practice and associated factors for health Care Professionals towards PEP in Debre Markos Town Public Health Institutions, Feb-Mar. 2017.

\begin{tabular}{|c|c|c|c|c|c|c|}
\hline \multirow{2}{*}{\multicolumn{2}{|c|}{ Variables }} & \multicolumn{2}{|c|}{ Took PEP } & \multirow{3}{*}{ P value } & \multirow{3}{*}{$\begin{array}{c}\text { COR }(95 \% \mathrm{Cl}) \\
1\end{array}$} & \multirow{3}{*}{$\begin{array}{c}\text { AOR }(95 \% \mathrm{Cl}) \\
1\end{array}$} \\
\hline & & \multirow{2}{*}{$\begin{array}{c}\text { Yes } \\
3(30.0 \%)\end{array}$} & \multirow{2}{*}{\begin{tabular}{c|} 
No \\
$7(70.0 \%)$
\end{tabular}} & & & \\
\hline \multirow{7}{*}{ Profession } & Medical Doctor & & & & & \\
\hline & $\begin{array}{l}\text { Emergency } \\
\text { Surgeon }\end{array}$ & $1(50 \%)$ & $1(50 \%)$ & 0.769 & $2.33(0.11-50.98)$ & $1.67(0.05-50.18)$ \\
\hline & Nurse & $17(47.2 \%)$ & $19(52.5 \%)$ & 0.481 & $2.09(0.47-9.38)$ & $1.82(0.35-9.56)$ \\
\hline & Midwife & $2(28.6 \%)$ & $5(71.4 \%)$ & 0.947 & $0.93(0.11-7.82)$ & $0.92(0.09-10.06)$ \\
\hline & Laboratory & $6(60 \%)$ & $4(40 \%)$ & 0.278 & $3.50(0.55-22.30)$ & $3.09(0.40-23.70)$ \\
\hline & Anesthetists & 0 & $1(100 \%)$ & 1.000 & 0.00 & 0.00 \\
\hline & Public Health & 0 & $1(100 \% 0$ & 1.00 & 0.00 & 0.00 \\
\hline \multirow{3}{*}{ Service year } & $\leq 5$ years & $14(37.8 \%)$ & $23(62.2 \%)$ & & 1 & 1 \\
\hline & $6-10$ years & $13(59 \%)$ & $9(41 \%)$ & 0.26 & $2.37(0.81-6.98)$ & $2.111(0.58-7.69)$ \\
\hline & $>10$ years & $2(25 \% 0$ & $6(75 \%)$ & 0.34 & $0.55(0.11-3.11)$ & $0.406(0.06-2.63)$ \\
\hline \multirow{2}{*}{ Training } & Yes & $12(33.3 \%)$ & $24(66.7 \%)$ & & 1 & 1 \\
\hline & No & $17(51.8 \%)$ & $14(48.2 \%)$ & 0.16 & $2.43(0.90-6.54)$ & $2.32(0.71-7.51)$ \\
\hline \multirow{2}{*}{ Chew chat } & Yes & $1(16.7 \%)$ & $5(83.3 \%)$ & & 1 & 1 \\
\hline & No & $28(45.9 \%)$ & $33(54.1 \%)$ & 0.601 & $4.24(0.47-38.49)$ & $1.92(0.16-22.05)$ \\
\hline
\end{tabular}


Knowledge, attitude, practice and associated factors towards post exposure prophylaxis to HIV infection among health care professionals in Debre Markos town public health institutions, Northwest Ethiopia, 2017

Table 8.Work environment and behavioral characteristics of Health Care Professionals in Debre Markos Town Public Health Institutions, Feb-Mar. 2017.

\begin{tabular}{|l|c|c|c|}
\hline Work environment and behavioral characteristics & Response & Frequency & Percent (\%) \\
\hline \multirow{2}{*}{ know about PEP guideline } & Yes & 104 & 51.5 \\
\hline Existence of written protocol for reporting exposure to HIV/ & No & 98 & 48.5 \\
\cline { 2 - 3 } AIDS risk factors at work place & Yes & 84 & 41.6 \\
\hline \multirow{2}{*}{ Drink alcohol before you go to work place } & Yes & 118 & 58.4 \\
\hline \multirow{2}{*}{ Chew chat } & No & 194 & 4.0 \\
\hline \multirow{2}{*}{ Smoke cigarette } & Yes & 7 & 96.0 \\
\hline
\end{tabular}

\section{Discussion}

In this study, all study participants (100.0\%) have heard about PEP for HIV which is higher as compared to previous studies like a research conducted in Nigeria tertiary hospital (90.4\%), and in Addis Ababa city $83.1 \%$ respondents were heard about HIV PEP [19,22]. This is might be due to difference in period of conduction and training opportunity.

The study show that $78.2 \%$ of the total respondents should initiate PEP within one hour after exposure, which is higher than other findings $(22.3 \%)$ from study conducted in Mulago Hospital in Uganda [20]. But, study conducted in Gondar University Hospital, $50.8 \%$ of respondents stated the exact time when to initiate PEP [23]. The difference might be because of study design and training opportunity.

A study conducted among HCWs in Gondar University Hospital showed that $36.9 \%$ of the respondents had less knowledge [23]. The respondents with poor knowledge account $36.1 \%$ in this study which similar to a study done in Gondar University Hospital. However, this level of poor knowledge cannot be considered low.

This study showed that majority of the respondents $(69.8 \%)$ had favorable attitude towards PEP for HIV when compared to the study conducted among health care workers in Gondar, North West Ethiopia (75.4\%) had good attitude toward the PEP [23] which indicated that it is better than the present study. This is might be due to difference study area and design.

A study conducted in University of Benin
Teaching Hospital, Benin City, Nigeria, among Dental Surgeons revealed that $96.3 \%$ of the participants were agreed on the importance of PEP for HIV/HBV [24]. In this study (97\%) the participants agreed on the importance of PEP for HIV was similar to the study done in Nigeria.

In this study, $33.2 \%$ of the health professionals were exposed for HIV/AIDS risky conditions. This finding is similar with the study done in Gondar (33.8\%) and lower than a study done in Jimma zone (68.5\%) [23,18].

As part of occupational safety measures, $56.7 \%$ of exposed HCWs didn't received PEP for their exposures against HIV/AIDS risk factors. This finding is better than a study done in Jimma Zone (81.6\%) where as it is lower than a study done in Gondar University Hospital $(25.7 \%)$ [23,18]. This is may be because of difference in period of conduction, study design, study area and sample size.

Study conducted in Mangalore, India, among Interns of a Medical College; (23.5\%) Knew the first aid measures following exposure and approximately $57.6 \%$ expressed their knowledge related to the application of antiseptics to the injured site [21]. In this study $68.6 \%$ of the respondents washed with soap and water. But, $14.9 \%$ of respondents squeezed for more bleeding and washed with alcohol or disinfectant. This finding is better than a study done in Mangalore, India this is might be because of difference study population and study period.

A study conducted in Gondar city, Northwest Ethiopia, revealed that the major reason for individuals who didn't receive PEP following 
their exposure were negligence (49.6\%) and whose HIV test result was negative 31.4\% [25]. In this study, the reason who didn't receive PEP following their exposure was similar to the study done in Gondar.

This study shows that profession and level of attitude were found to be significant association with PEP knowledge (AOR $=0.111,95 \% \mathrm{CI}$ .019 -.638) and $(\mathrm{AOR}=3.165,95 \%$ CI 1.549$6.467)$ respectively, which could be probably explained by the PEP was taught as a part of the curriculum and difference academic year. Knowledge status of respondents had significant association with PEP attitude label $(\mathrm{AOR}=3.21$, 95\% CI (1.60-6.45).

\section{Conclusion}

Some unnecessary measures were taken by health professionals after exposure like squeezed the site for more bleeding and washed with alcohol and disinfectant. Despite adequate knowledge and favorable attitude towards PEP for HIV, this study revealed that there were delay initiation, low use and incomplete use of the prescribed PEP. So, health care personnel need to improve their practice on PEP of HIV through different training program related to PEP of HIV.

\section{Recommendation}

1. Health facilities should strengthen and integrate routine PEP services through providing training to all health professionals.

2. Health facilities should make available PEP guidelines within their workplace and standardize written PEP policies for the management of occupational exposure.

3. To increase the utilization of PEP, all health professionals should be trained on PEP.

4. Further study with different design should be done.

\section{Acknowledgement}

We would like to thank Debre Markos Referral Hospital and Debre Markos Town District Health Office for giving necessary information about the study area and study population.

We would like to thank study participants' willingness to participate in the study and data collectors.

We would like to thank Debre Markos University, College of medicine and health science for giving us ethical clearance to conduct this research. 


\section{REFERENCES}

Federal Ministry of Health infection prevention and patient safety, Reference Manual for service providers and management in health care facilities of Ethiopia, Addis Ababa Ethiopia (2011).

Everline M, Zipporah N, Peter W, Jared O. Prevalence and factors associated with percutaneous injuries and splash exposures among health-care workers in a provincial hospital, Kenya (2010).

Ashebir Ayalew. Assessment of knowledge attitude and practice and factors associated with PEP service utilization among health professionals, Addis Ababa, EPHA (2010).

Ministry of Health Guideline for management of opportunistic infections and Anti retro viral therapy in adolescent and adults in Ethiopia, federal ministry of health Ethiopia (2008).

Federal Ministry of Health, Infection prevention and patient safety, Reference Manual for service providers and management in health care facilities of Ethiopia, Addis Ababa Ethiopia (2011).

WHO Guidelines on post-exposure prophylaxis for HIV and the use of co-trimoxazole prophylaxis for HIV-related infections among adults, adolescents and children: recommendations for a public health approach - December 2014 supplement to the 2013 consolidated guidelines on the use of antiretroviral drugs for treating and preventing HIV infection. Geneva: World Health Organization (2014).

Federal Ministry of Health, National comprehensive HIV care and treatment training for health care providers. Participant manual, Addis Ababa Ethiopia (2014).

Kuhar DT, Henderson DK, Struble DKA, et al. Occupational Exposures to HIV and Recommendations for Post exposure Prophylaxis, the U.S. Public Health Service Working Group, Infection Control and Hospital Epidemiol. 34(9) (2013).
Federal Ministry of Health, Infection prevention and patient safety, Reference Manual for service providers and management in health care facilities of Ethiopia, Addis Ababa Ethiopia (2011).

Ministry of Health and Family Welfare: Government of India National AIDS Control Organization: Management of Occupational exposure including Post exposure prophylaxis for HIV. New Delhi: NACO (2009).

Ikram B, Ibtihal F, Amna M, Asma M, Emad S. Knowledge, Attitudes and Practices of Health Care Workers in Benghazi, Libya towards Post Exposure Prophylaxis for HIV (2013).

Tsegabrhan G, Gerezgiher B. HIV Post-Exposure Prophylaxis Use and Associated Factors among Health Professionals of Governmental Health Institutions in Mekelle Town, Tigray region, north Ethiopia, Humera Hospital, ART center, Tigray, Ethiopia, J. AIDS Clin Res (2014).

Debre Markos Town Public Health Institution report, (2009).

Samuel Omondi O,Supattra S, Bang-on T. :Awareness of occupational postexposure prophylaxis HIV infection among health workers in Nyanza province, Kenya, J Public Health Dev. 11(2) (2013).

Ali S, Andrew F. Prophylaxis of HIV infection, British Medical Bulletin. 108(1) (2013).

Okechuku EF. The knowledge and practice of standard precautions among health care workers in public secondary health facilities in Abuja, Nigeria University of South Africa, (2009).

Reshma R, Prithviraj DR, Basavarajaiah DM, Vidyashankar N. Assessment of knowledge on post exposure prophylaxis in HIV among dental healthcare workers. 2(2), 31-36 (2013).

Ekundayo OT, Ogbaini-Emovon EA. Knowledge, attitude and practice of HIV infection PEP among resident Docrtors in a Tertiiary Hospital,Benin City, Nigeria. Int J Comm Res (2014).
Alenyo R, Fualal J, Jombwe JJ. Knowledge attitude and practice of staffs towards post exposure prophylaxes for HIV infection at Mulango hospital in Uganda. East and central African J Surgery, 14(2), 99-102 (2009).

Shuvankar M, Agnihotri B, Biswanath $S$, et al. Knowledge and Practice of Standard Precautions and Awareness Regarding Post-Exposure Prophylaxis for HIV among Interns of a Medical College in West Bengal, India; Oman Med. J. 28(2), 141-145 (2013).

Nimbulkar GC, Garcha V, Shetty V, Bhor KB. Assessment of knowledge, attitude and practice towards Human immunodeficiency virus (HIV) post exposure prophylaxis (PEP) amongst academicians, interns and students in two dental and medical colleges-Pune city. Int J Recent Scientific Res 7(8), 12909-12913 (2016).

Tadesse A. Assessment of Health Care Workers Occupational Exposure to HIV and Post-Exposure Prophylaxis (PEP) in Health Centers and Hospitals, Addis Ababa university school of public health Addis Ababa, Ethiopia July, 2008

Biniam M, Wubet B, Sebesbe K, et al. Assessment of knowledge, attitude and practice towards post exposure prophylaxis for HIV among health care workers in Gondar, North West Ethiopia, BMC Public Health 13, 508 (2013).

Mercy O, Saheeb BD. Assessment of knowledge, attitude and practice of post-exposure prophylaxis against blood-borne viral infection among dental surgeons in a teaching hospital, in University of Benin Teaching Hospital, Benin City, Nigeria, Southern African Journal of Infectious Diseases (2016).

Getahun K, Daniel H. Post exposure prophylaxis uptake against exposure to HIV/AIDS risk factors in healthcare settings was very low, University of Gondar, Gondar, Ethiopia (2011). 